* Doutor e Mestre em Direito pela Universidade Federal do Paraná - UFPR. Bacharel em Direito pela Universidade Estadual de Ponta Grossa - UEPG. Professor Adjunto da Universidade Federal de Mato Grosso do Sul - UFMS, Campus de Três Lagoas. Líder do Núcleo de Pesquisa em Estado e Política - NUPEPOL. Coordenador do Projeto de Pesquisa "Observatório Constitucional".

** Doutora em Direito pela Universidade Federal do Paraná - UFPR. Bacharel em Direito pela Universidade Estadual de Ponta Grossa UEPG. Professora Adjunta da Universidade Federal de Mato Grosso do Sul - UFMS, Campus de Três Lagoas. Coordenadora do Projeto de Pesquisa "Direitos Humanos, Democracia e Jurisdição Internacional”.

\section{Direito Ao Protesto, Manifestações Violentas E Direito De Resistência.}

\author{
Right To Protest, Violent Protests And Right To Resist.
}

\section{Luís Fernando Sgarbossa* Geziela Iensue**}

Como citar: SGARBOSSA, Luís Fernando; IENSUE, Geziela. DIREITO AO PROTESTO, MANIFESTAÇÕES VIOLENTAS E DIREITO DE RESISTÊNCIA. Revista do Instituto de Direito Constitucional e Cidadania - IDCC, Londrina, v. 4, n. 2, p 140162, dez, 2019. ISSN: 2596-0075.

https://doi.org/10.48159/revistadoidcc.v4n2.sgarbossa.iensue

Resumo: O presente artigo pretende explorar, a partir de um sucinto resgate das manifestações ocorridas no Brasil em períodos históricos relativamente recentes, questões importantes e complexas em matéria de Filosofia Política e Constitucional, cuja reflexão foi propiciada por diversos acontecimentos. Assim, entre outros aspectos, o estudo pretende examinar brevemente o direito fundamental ao protesto como componente dos regimes democráticos e sua abrangência, especialmente no que diz respeito à prática de atos de violência e de depredação de bens públicos e privados praticados por alguns dos participantes de manifestações como as ocorridas especialmente no ano de 2013. Pretende investigar especialmente se os atos de violência praticados por ocasião de manifestações poderiam porventura encontrar amparo no denominado direito de resistência, tema obscurecido e em parte negligenciado na atual teoria constitucional. $\mathrm{O}$ artigo resgata alguns dos requisitos substanciais e procedimentais e limites apontados pela literatura para o exercício do controverso direito, e busca aplicar os mesmos para examinar os atos de violência ocorridos naquelas manifestações. $O$ artigo conclui pela impossibilidade do reconhecimento da cessação do dever de obedecer ao direito naquela situação, sem recusar a possibilidade de sua caracterização em outras circunstâncias mais graves.

Abstract: This paper explores important and complex questions
in the field of Political and Constitutional Philosophy starting
from a brief review of the manifestations that occurred in Brazil in
relatively recent historical periods. Thus, among other aspects, the
study intends to briefly examine the fundamental right to protest
as a component of democratic regimes and their scope, especially
with regard to the practice of acts of violence and the ravage of 
public and private property committed by some of protesters such as occurred especially in 2013. It intends to investigate in particular whether acts of violence committed during protests could possibly be supported by the so-called right to resist, a subject that is obscured and partly neglected in current Constitutional Theory. The article rescues some of the substantial and procedural requirements and limits pointed by the literature for the exercise of the controversial right, and seeks to apply them to the acts of violence that occurred in those manifestations. The article concludes by the impossibility of recognizing the cessation of the duty to obey the law in that concrete situation, without rejecting the possibility of its characterization under other more serious circumstances.

Palavras-Chave:Direito ao protesto. Violência. Direito de resistência.

Key-words:Right to protest. Violence. Right to resist. 


\section{INTRODUÇÃO.}

Durante o ano de 2013 a população brasileira saiu às ruas em protestos que ocorreram em inúmeras capitais e municípios em todo o território nacional, protestos aos quais os cidadãos acorreram aos milhares, em um movimento social sem precedentes na história recente do país.Os primeiros protestos ocorreram por volta em meados do mês de junho do ano de 2013, inicialmente envolvendo pleitos relativos ao aumento das tarifas do transporte público, sendo um dos protagonistas o Movimento Passe Livre, sendo registrados nas cidades de São Paulo, Rio de Janeiro, Natal, Goiânia, Brasília e Porto Alegre, e sendo frequente terminarem em tumulto e depredação de ônibus e estações de metrô. ${ }^{1}$

Poucos dias depois, novos protestos e tumultos foram registrados na cidade do Rio de Janeiro, culminando e depredação e prisões, assim como em São Paulo, com notável incremento da violência, agora tendo por objeto também agências bancárias.Em 17 de junho verificam-se massivas manifestações nas principais cidades do país, e o escopo das manifestações torna-se mais amplo, abrangendo além das questões originais uma série de pautas, como a corrupção, propostas de emendas constitucionais e outros. No mesmo dia inicia-se o cerco à Assembleia Legislativa do Rio de Janeiro. ${ }^{2}$

Apesar de algumas concessões feitas por alguns governos a partir do mês de junho, os protestos e manifestações continuam por todo o país nos dias seguintes, em cidades como Belo Horizonte e Salvador (22 de junho), Porto Alegre (24 de junho), São Paulo, Rio de Janeiro, Niterói, Aracaju, Florianópolis e Sumaré (25 de junho), entre outros, chegando-se a registrarem-se mortes em nas cidades de Porto Alegre e Belo Horizonte.

No período verificam-se diversas tentativas do governo e dos poderes constituídos em responder de algum modo ao clamor popular, por meio do cancelamento de aumentos das tarifas de transporte público, bem como da rejeição da Proposta de Emenda à Constituição de n. 37, entre outras medidas ou propostas e recuos. Outros protestos e tumultos ocorreram, ainda, em Fortaleza (27 de junho), São Paulo (28 de junho), Belo Horizonte (29 de junho), Rio de Janeiro (30 de junho e $03,04,11$ e 14 de julho).

Independentemente dos acontecimentos subsequentes, cujasconsequências se fizeram sentir de maneira intensa nos anos seguintes e até a atualidade, os acontecimentos verificados no país durante o ano de 2013, que parecem ter transformado a democracia brasileira, trazem à baila uma miríade de questões constitucionais da maior grandeza que merecem ser objeto de reflexão.

Alguns aspectos que não deixaram de chamar a atenção no que diz respeito aos protestos em questão foi seu caráter majoritariamente apartidário, a ausência de uma única reivindicação central, e, especialmente, a intensidade e a gravidade dos distúrbios que ocorreram por ocasião das manifestações, seja durante, seja ao final das mesmas.

Um cenário não raro devastador se seguia a diversas horas de confronto entre policiais

1 Fonte: http://veja.abril.com.br/cronologia/protestos-no-brasil/index.html.Acesso em: 29.01.2014.

2 Fonte: http://veja.abril.com.br/cronologia/protestos-no-brasil/index.html. Acesso em: 29.01.2014. 
e manifestantes, com direito a depredação do patrimônio público e da propriedade popular, embora, segundo a imprensa, os atos de violência e depredação não possam ser atribuídos a todos os manifestantes, mas apenas a uma parcela dos mesmos.Os pontos de vista sobre o aspecto violento em que se degeneraram os protestos foram bastante díspares, assim como a argumentação a respeito das causas dos atos de violência.

Manifestantes e forças de segurança pública trocaram acusações quanto à responsabilidade pelo início dos atos de violência, sendo que alguns grupos- especialmente os denominados "Black blocs" - foram precipuamente responsabilizados pelos atos de violência por parte de autoridades e imprensa.As manifestações, os distúrbios e as diferentes opiniões acerca dos referidos acontecimentos, especialmente envolvendo questões como as levantadas por ocasião dos episódios de proibição do uso de máscaras por ocasião das manifestações levantam importantes questionamentos em matérias constitucionais.

Entre tantas outras questões de Filosofia Política e Constitucional passíveis de serem levantadas a partir dos referidos acontecimentos uma se destaca, qual seja, saber se os atos de violência perpetrados por ocasião das manifestações podem ser plausivelmente considerados como abarcados pelo âmbito de proteção do direito ao protesto, constitucionalmente previsto, ou se dele exorbitariam.

Além disso, parece plausível buscar verificar se os referidos atos de violência encontrariam abrigo no controvertido direito de resistência e, ainda, até que ponto a democracia se compatibiliza com o recurso a atos violentos. Inicialmente convém examinar de que modo o direito ao protesto vincula-se ao regime democrático.

\section{DEMOCRACIA LIBERAL, DIREITO AO PROTESTO, REPRESSÃO E CRIMINALIZAÇÃO.}

A democracia contemporânea revela-se, além de representativa, liberal, pelo que, além de instituições aptas a permitir a participação dos governados no poder - notadamente eleiçõese instituições representativas - necessariamente compreende diversos direitos e liberdades que possuem inegável dimensão política e evidente conexão com o regime democrático.

Assim, apesar das diversas concepções possíveis de democracia em nível conceitual, e dos diferentes regimes democráticos em nível operacional, direitos como a liberdade de informação, de opinião e de expressão do pensamento, a liberdade de imprensa, a liberdade de associação e notadamente - o direito ao protesto, constituem parte integrante daqueles regimes de acordo com os mais autorizados pontos de vista.

As teorizações de Robert Dahl sobre a democratização fazem com que ele considere as poliarquias $^{3}$ ou democracias reais como constituídas de pelo menos duas dimensões, a saber, a

3 Para o autor uma poliarquia consiste em um regime político caracterizado pela responsividade dos governantes relativamente às preferências do povo ou eleitorado, sendo constituído, como se verá, pelas dimensões essenciais da participação e da oposição. Ao conceito de poliarquia opõem-se outros, como os de hegemonia fechada, hegemonia inclusiva ou oligarquia competitiva, todos caracterizados por defeitos de inclusividade e/ou liberalização, além de várias formas intermediárias, tais como as quase-poliarquias (DAHL, 2012). 
inclusividade e a liberalização.A primeira, também denominada participação, traduz a exigência de que um regime político, para revelar-se responsivo à vontade popular, deve promover uma ampla inclusão de pessoas, o que se traduz em mecanismos que tornem o governo dependente do assentimento dos governados.

A liberalização, por sua vez, consiste na exigência de que o regime político, para caracterizarse como poliarquia ou, usando uma expressão mais comum, democracia, tolere a oposição aos governantes, o que se traduz na existência de diversas condições, como a garantia de liberdade de informação, expressão, manifestação ou protesto, associação e outros (DAHL, 2012).

Inúmeros outros autores evidenciam claramente a irredutibilidade do conceito contemporâneo de democracia à simples existências de eleições periódicas ou mesmo da operação da regra da maioria.Desse modo, resta bastante evidente que diversas liberdades, especialmente o direito ao protesto ou à manifestação, constituem institutos inerentes a uma democracia e que não podem ser recusados em um regime que assim se pretenda qualificar.

Nada obstante, como ademais ocorre com todos os direitos e liberdades fundamentais, a existência de um direito fundamental e a vagueza e imprecisão dos dispositivos constitucionais que lhe dão assento fazem com que seu âmbito ou área de proteção e, consequentemente, as condutas por ele protegidas, sejam bastante incertos.

Além disso, também como ocorre com outros direitos e liberdades, podem se verificar conflitos entre a liberdade de manifestação ou de protesto e outros direitos ou liberdades fundamentais, ou ainda outros bens constitucionalmente tutelados, o que origina problemas de complexidade formidável e de difícil resolução.

Assim poder-se-ia pretender examinar a amplitude que tem sido conferida ao âmbito/área de proteção do direito ao protesto para buscar esclarecer se os atos de violência praticados durante as manifestações poderiam ser considerados, do ponto de vista jurídico, como desdobramentos legítimos do referido direito ou se, contrariamente, dele exorbitariam, não encontrando abrigo no mesmo, e revelando-se ilícitos e abusivos.

Além disso, poder-se-ia propor o exame de temática a partir da doutrina jusfilosófica da Europa continental, assim como a do mundo anglo-americano, que tem se dedicado a buscar respostas para os intrincados problemas que se originam da indefinição dos contornos ou limites dos direitos fundamentais ou das liberdades básicas.

No entanto o presente artigo optará por um caminho um tanto diverso, sem negar importância à referida abordagem. Partindo-se da pressuposição de que o direito ao protesto abrange apenas o protesto pacífico ${ }^{4}$,buscar-se-á examinar possíveis consequências do emprego da violência nos protestos, para após examinar a plausibilidade de uma tese que legitime tais atos com base no

\footnotetext{
4 Diversas constituições consagram, expressa ou implicitamente, um direito ao protesto pacífico. Há entendimentos doutrinários e jurisprudenciais no sentido de que o exercício legítimo do direito ao protesto pressupõe o caráter pacífico deste, restando excluído o recurso à violência ((PERSONERIA DE MEDELLIN, 2010).
} 
direito de resistência. ${ }^{5-6}$

$\mathrm{O}$ direito ao protesto pode ser concebido como uma liberdade política fundamental e comc uma dimensão coletiva da liberdade de expressão, constituindo um importante meio de exercícic dos direitos políticos que historicamente embasa importantes movimentos cívicos e atos de apoic ou protesto ${ }^{7}$ (PERSONERIA DE MEDELLÍN, 2010).

As crises constitucionais e institucionais que frequentemente assolam diversos países como aquelas que varreram o Oriente Médio no fenômeno que ficou conhecido pela alcunha d€ "primavera Árabe", ocorrido há cerca de uma década - costumam trazer à reflexão, de diversas maneiras, os problemas relativos a importantes direitos como o direito ao protesto ${ }^{8}$ (PERSONERIA DE MEDELLÍN, 2010).

A título de exemplo, no ano de 2009, manifestações populares em quadrantes do planeta tãc diferentes quanto Honduras, Irã e China, faziam com que organismos como a Anistia Internacional se preocupassem com a afirmação do direito ao protesto pacífico contra a repressão das autoridades governamentais $^{9}$ (LACHAPELLE; WAY; LEVITSKY, 2012).

$\mathrm{Na}$ América Latina é cabível recordar, entre outros casos, os protestos ocorridos na Argentina durante a década 90 do século passado e, notadamente, o conflito ocorrido no ano de 2001, que resultou em 30 mortes(ARTESE, 2009). De se recordar, ainda, manifestações, com bloqueio de estradas e "panelaços", no mesmo período, em países como Paraguai, Peru, Equador, Bolívia, Haiti ${ }^{10}$ (GARGARELLA, 2007).

5 Digno de nota que também muitos textos preveem expressamente o direito ao protesto pacífico. Cite-se, como ilustração, o art. 37 da Constituição colombiana de 1991: "Qualquer parcela do povo pode se reunir e se manifestar pública e pacificamente. Apenas a lei poderá estabelecer expressamente os casos nos quais será possível limitar o exercício deste direito". No mesmo sentido, evidentemente, revela-se dispositivo constitucional equivalente da Constituição Federal brasileira de 1988, em seu art. 5º, inciso XVI. (BRASIL, 1988, ART. $5^{\circ}$, XVI).

6 Poderiam ser entendidos, em princípio, como protestos ou manifestações pacíficas aquelas que não representem risco grave à vida, à propriedade ou a liberdade das pessoas, embora, obviamente, possam causar transtornos momentâneos, como o bloqueio de uma via pública.

7 Exatamente nestes termos as ponderações da Sentença C-024 de 1994 da Corte Constitucional da Colômbia (PERSONERIA DE MEDELLÍN, 2010).

8 Entre outros, cabe referenciar os protestos no Egito e no Irã: "Em 2009 e 2011, respectivamente, regimes autoritários no Irã e Egito foram ameaçados por mobilizações de oposição sem precedentes. No Egito centenas de milhares de pessoas - inspiradas na queda de Ben Ali na Tunísia - protestaram por todo o país no início de 2011, buscando pôr fim ao governo do Presidente Hosni Mubarak. De forma semelhante, na República Islâmica do Iran (RII), centenas de milhares de manifestantes tomaram as ruas após uma eleição presidencial fraudulenta no ano de 2009, atirando o regime islâmico em "pânico e medo." Embora os movimentos de protesto tenham ostentado numerosas similaridades nos dois países, seus resultados em termos de regime foram significativamente diversos. Enquanto os protestos egípcios resultaram na resignação de Mubarak e na realização das primeiras eleições verdadeiramente competitivas do país, no Irão o regime islâmico resistiu a grandes quantidades de protestos de larga escala, e eventualmente esmagou o movimento de oposição sem quaisquer concessões sérias"(LACHAPELLE; WAY; LEVITSKY, 2012, p. 02).

9 Quanto aos protestos no Irã contra os resultados das eleições as preocupações tinham por foco a prisão e possível tortura de diversos líderes dos protestos, bem como a morte de dezenas de pessoas e outros atos de violência durante as manifestações. Atos de violência no protesto pelo retorno do Presidente deposto de Honduras, Manuel Zelaya, culminaram na morte de um jovem, no mês de julho, e houve decretação de estado de exceção e suspensão de direitos e garantias fundamentais. $\mathrm{O}$ caso que parece mais grave é o chinês, no qual os protestos na região autônoma de Xinjiang culminaram na morte de 140 pessoas, também em julho.Veja-se o editorial do periódico (ANISTIA INTERNACIONAL. El derecho a la protesta pacífica.Amnistía Internacional Revista sobre Derechos Humanos, Madrid, n. 98, 2009).

10 Este texto foi publicado também na forma de capítulo de livro em obra coletiva organizada pelo mesmo autor, dedicada especificamente ao tema da desobediência ao direito. Confira-se GARGARELLA, Roberto (org.). El derecho a resistir el derecho. Madri: Miño Dávila, 2005. 
Mesmo a Europa e os Estados Unidos da América têm sido, vez por outra, sacudidos com fortes protestos de movimentos como o Indignez vous ou o Occupy Wall Street, geralmente em movimentos altermundialistas e políticas neoliberais, entre outros ${ }^{11}$ (PERSONERIA DE MEDELLÍN, 2010). Bem mais recentemente, já em 2019, cabe fazer referências às intensas situações vivenciadas em Hong Kong, Colômbia, Bolívia e Chile.

O mesmo vale para inúmeros outros países, cuja nominação seria exaustiva e desnecessária. Em todos estes casos resta patente ser bastante comum que o direito ao protesto entre em conflito com direitos ou interesses de terceiros e, não raro, que venha a ser regulamentado ou restringido(ARTESE, 2009) efrequentemente ser reprimido com violência (extrema, em alguns casos).

A Personería de Medellín, órgão de promoção e defesa dos direitos humanos, em texto dedicado ao tema do direito ao protesto, sustenta que muitas vezes os métodos utilizados para a repressão de atos de violência por vezes realizados nos protestos ${ }^{12}$ ao redor do mundo revelam-se piores do que os atos legítimos em situações de guerra segundo o Direito Internacional Humanitário(PERSONERÍA DE MEDELLÍN, 2010).

$\mathrm{Na}$ tentativa de responder até que ponto pode ir o direito ao protesto quando se verifique em conflito com outros direitos, algumas observações devem ser feitas, como, exemplificativamente, a inexistência de direitos absolutos, de um lado, e a existência de estados de necessidade ${ }^{13}$ justificáveis, de outro.

Um dos problemas prementes no emprego de meios violentos nos protestos é a legitimação de eventuais interesses em regulamentar ou restringir tal direito fundamental, ou, ainda, uma percepção de abuso ou ilegitimidade por parte da opinião pública e a possibilidade sempre presente de repressão pelas autoridades governamentais. Tal recurso, portanto, parece extremamente perigoso, na medida em que pode enfraquecer a própria instituição do direito ao protesto(ARTESE, 2009).

Na Argentina, que conheceu fortes ondas de protestos na década de 1990 e início da década de 2000, os bloqueios de vias públicas por piquetes passaram a ser considerados como práticas nocivas às instituições democráticas, ao funcionamento da economia e à normalidade da vida

11 A regra, em todos os quadrantes, é a repressão estatal.Matías Artese, em estudo dedicado à criminalização do direito ao protesto na Argentina, evidencia a conexão de importantes protestos sociais, como aqueles ocorridos naquele país durante a década de 1990, à reforma do Estado para atender a imperativos das políticas neoliberais (ARTESE, 2009).

12 PERSONERÍA DE MEDELLÍN adiante aduz: "Na medida em que crescem os protestos sociais, aumentam as críticas de cidadãos e cidadãs relativamente a seu exercício, fazendo parecer que os que ostentam o poder, de maneira hábil, estão transferindo a discussão da relação cidadania-Estado para a relação cidadania-cidadania, razão pela qual, na América Latina, são mais comuns os mecanismos que instauram cidadãos e cidadãs contra aqueles que exercem o direito ao protesto e, ao mesmo tempo, servem de justificação para regular ou limitar o direito ao protesto.” (PERSONERÍA DE MEDELLÍN, 2010, p. 134). É o caso, por exemplo, do processo de criminalização dos bloqueios de vias públicas por piquetes na Argentina. Veja-se,(ARTESE, 2009).

13 Poder-se-ia cogitar em estado de necessidade, como se verá adiante ao examinar o direito de resistência: “de modo semelhante, se os protestos ocorrem porque se esgotaram as vias jurídicas, o Estado é inoperante ou as condições de violação se mantêm, o protesto seria fundamentado em um estado de necessidade. Assim, por exemplo, no caso colombiano, quando o protesto foi realizado por desabrigados ou desabrigadas, uma população que foi submetida a uma situação de extrema vulnerabilidade, como indica a Corte Constitucional, podem se ver compelidos por seu notório estado de necessidade, a realizar ações de protesto que em alguns casos podem vir a violar os direitos de outros ou outras" (PERSONERÍA DE MEDELLÍN, 2010, p. 136). A temática das situações de necessidade extrema será retomada adiante com base no pensamento de Roberto Gargarella. 
cotidiana, sofrendo um processo de criminalização baseado em tal visão ${ }^{14}$.

Outro tema de abordagem necessária ao tratar do tema em exame e que se fez sentir em protestos da Europa ao Brasil é a marcante atuação dos denominados "Black Blocs", designação normalmente atribuída a grupos antifascistas, de atuação mais radical. Tais grupos têm marcado presença em muitos protestos ao redor do globo, pelo que se tem notícia a partir das décadas de 1980 e $1990^{15}$ (DUPUIS-DERI, 2004).

A atuação de tais blocos é controvertida e eles têm marcado sua atuação por ocasião de manifestações populares pelo confronto com as forças de segurança pública e, eventualmente, pela depredação de patrimônio público e privado, especialmente contra empresas que representam o poder econômico e financeiro, como instituições bancárias, redes de fast-food e outros.

Além da própria discussão sobre a moralidade ou legalidade da utilização de recursos violentos por ocasião de protestos legítimos, existem aspectos problemáticos em tal prática, segundo a visão de alguns, de pontos de vista políticos e práticos, entre outros. Assim, há quem considere que a degeneração das manifestações em violência deformaria a visão da mídia e da sociedade sobre os movimentos, além de poder gerar efeitos nocivos a médio e longo prazo, além de facilitar a repressão e a criminalização dos movimentos (DUPUIS-DERI, 2004).

Independentemente da posição que se adote sobre a legitimidade ou ilegitimidade dos atos de violência praticados no contexto de protestos e manifestações, deve-se observar que mesmo em protestos ou manifestações que possam ser considerados como tendo degenerado para atos ilícitos ou abuso de direito impõe-se a garantia dos direitos humanos relativamente aos envolvidos em tais atos.

Assim, o direito à vida e à integridade física, entre outros, não podem ser violados sob o pretexto de proteção à propriedade privada ou cumprimento da lei ${ }^{16}$, exigindo-se proporcionalidade e comedimento por parte das forças de segurança pública incumbidas do restabelecimento da normalidade e da proteção de outros bens e interesses constitucionalmente tutelados eventualmente em tensão ou colisão com o direito ao protesto.

Importante registrar, ainda, a opinião segundo a qual embora as manifestações e protestos não se enquadrem na definição de conflito armado para fins do Direito Internacional Humanitário, as normas deste seriam aplicáveisàs situações de conflito mencionadas, feitas a devidas adaptações. Consequentemente, segundo tal ponto de vista, impõe-se às autoridades responsáveis pela manutenção da ordem, pelo cumprimento da lei e pela repressão aos atos ilegais que observem

14 De acordo com Artese (2009) as autoridades argentinas, com base em uma visão de conflito entre o direito ao protesto e o direito à livre circulação, posicionaram-se unicamente em favor deste e em detrimento do primeiro. O mesmo enfatiza, ainda, que uma visão extremamente negativa das manifestações foi propagada a partir das autoridades e difundida pela imprensa.

15 A expressão parece ter tido sua origem na Alemanha em 1980 (Scharze Block). Como explica DUPUISDERI, "não há um Black Bloc, mas Black Blocs, cada um se formando por ocasião de uma manifestação para dissolver-se com ela. O tamanho dos Black Blocs varia de algumas dezenas a alguns milhares de indivíduos. Em certos casos, diversos Black Blocs estão simultaneamente ativos no seio de um mesmo evento de contestação, como se deu por ocasião das manifestações contra a Cúpula das Américas ocorrida em Québec, em abril de 2001". O autor também evidencia as divergências existentes dentro do próprio movimento altermundialista sobre a questão dos protestos violentos e da ação dos "Black Blocs"(DUPUIS-DERI, 2004, p. 79-80; 94).

16 Caso notável atual é o do Chile, onde se estima que mais de 200 pessoas tenham sido feridas nos olhos e mais de uma dezena delas tenham perdido a visão nos protestos de 2019, até agora. 
princípios como o da distinção, proporcionalidade e da reciprocidade. ${ }^{17}$

Por outro lado, importante observar que o conceito de perturbação ou ameaça à ordem pública a ser pretensamente preservado com a atuação das forças de segurança pública em situações de protestos ou manifestações com atos de violência não pode ficar na livre discricionariedade das autoridades.

Apesar de tudo, caso a premissa aqui assumida esteja correta, ou seja, da incompatibilidade (ao menos prima facie) do uso de violência com o direito ao protesto em um regime democrático, cabe investigar se os atos em exame seriam respaldados, eventualmente, pelo direito de resistência, que será examinado no tópico seguinte.

\section{RESGATE HISTÓRICO DO DIREITO DE RESISTÊNCIA.}

O direito de resistência corresponde a uma figura antiga no imaginário político, sendo compreendido genericamente como um direito de oposição dos súditos ou dos cidadãos em face do poder político com base em razões de justiça(CARVAJAL,1992).Eceizabarrena (1999)ensina que a ideia de direito de resistência remonta à Antiguidade, vislumbrando sua representação já no antagonismo entre a lei divina não escrita e a lei escrita da Polis, em Antígona, de Sófocles.

Reconhecido em diversos documentos de importância histórica ímpar, como na Declaração de Independência dos Estados Unidos da América de 1776 e na Declaração Universal dos Direitos do Homem e do Cidadão de $1879^{18}$, bem como no pensamento jusnaturalista de importantes filósofos, como Tomás de Aquino, Marsílio de Pádua, Francisco Suarez, Hugo Grócio, John Locke, o direito de resistência é um direito humano clássico, por vezes referido como direito de resistência à opressão (D’ANGELO, 1996) e que exerceu influência notável sobre o pensamento político e o

\footnotetext{
17 “A partir da lógica esboçada, o artigo $1^{\circ}$, comum aos quatro acordos de Genebra, obriga as altas partes contratantes a respeitar e a fazer respeitar em quaisquer circunstâncias o Direito Internacional Humanitário, pelo que "qualquer circunstância" pode abranger inclusive um protesto social no qual se apresentem situações de violação à legalidade. Se é assim, são utilizáveis tanto os princípios da distinção, proporcionalidade e não-reciprocidade, como o princípio referente a métodos e meios"(PERSONERÍA DE MEDELLIN, 2010,p. 137-138). Desse modo, seria imperativo às forças de segurança distinguir entre os manifestantes que praticam atos ilegais e aqueles que não os praticam, bem como, entre os primeiros, entre aqueles que abandonaram a prática dos atos relativamente aos demais que nela persistem. Em qualquer caso o uso da força deve ser proporcional, na medida do necessário ao restabelecimento da ordem e à cessação dos atos ilegais e, ainda, cessados estes, aquele também deve cessar.

18 A Declaração de Independência dos EUA de 1776 o reconhece ao afirmar que "Consideramos estas verdades como evidentes por si mesmas, que todos os homens são criados iguais, dotados pelo Criador de certos direitos inalienáveis, que entre estes estão a vida, a liberdade e a procura da felicidade. Que a fim de assegurar esses direitos, governos são instituídos entre os homens, derivando seus justos poderes do consentimento dos governados; que, sempre que qualquer forma de governo se torne destrutiva de tais fins, cabe ao povo o direito de alterá-la ou abolila e instituir novo governo, baseando-o em tais princípios e organizando-lhe os poderes pela forma que lhe pareça mais conveniente para realizar-lhe a segurança e a felicidade." A Declaração Universal dos Direitos do Homem e do Cidadão de 1879 consagra tal direito em seu art. $2^{\circ}$ : "O objetivo de toda associação política é a conservação dos direitos naturais e imprescritíveis do homem. Esses direitos são a liberdade, a propriedade, a segurança e a resistência à opressão." Mesmo documentos mais recentes fazem menção, ainda que indireta, à noção de direito de resistência. Assim, a título de exemplo, a Declaração Universal dos Direitos Humanos de 1948, em seus consideranda, consigna ser "essencial que os direitos humanos sejam protegidos pelo Estado de Direito, para que o homem não seja compelido, como último recurso, à rebelião contra tirania e a opressão". Sobre as razões de Thomas Jefferson para sustentar a resistência contra o governo britânico na Declaração de Independência. Suarez chegava a sustentar o tiranicídio e a visão de que somente se pode combater a força com a força. GARGARELLA, 2005).
} 
constitucionalismo ${ }^{19}$. Como ensina Roberto Gargarella ${ }^{20}$,

Até o final do século XVIII, e pela mão de John Locke, a resistência à autoridade apareceu como uma das quatro ideias que, me atreveriaa dizer, distinguiram o constitucionalismo em suas origens. Assim, a ideia de resistência tendeu a aparecer juntamente com a referência ao caráter inalienável de certos direitos básicos; à ideia de que a autoridade seria legítima na medida em que repousasse sobre o consentimento dos governados; e aquela segundo a qual o primeiro dever de todo governo seria o de proteger os direitos inalienáveis das pessoas. Em tal contexto - afirmava-se -o povo poderia legitimamente resistir e até mesmo derrogar o governo caso o último não tivesse sido consequente em relação ao respeito daqueles direitos básicos (GARGARELLA, 2005, p. 5).

Há que se reconhecer, no entanto, que a ideia de resistência à tirania foi particularmente importante no pensamento medieval, no qual encontra importantes precedentes aos autores modernos. ${ }^{21}$ Originalmente concebido como um direito natural, o direito de resistência tem até mesmo eventualmente sido positivado, através de seu reconhecimento em constituições. ${ }^{22}$

Gargarella (2010) refere-se à constitucionalização do mesmo na Constituição da Banda Oriental do Uruguai de 1813 e a Constituição mexicana de Apatzingán de 1814.São discutidos também os casos da Constituição alemã, portuguesa, argentina e outras. ${ }^{23}$

$\mathrm{O}$ autor argentino afirma que apesar dos variados matizes ideológicos dos defensores do direito de resistência, em geral os mesmos convergem no sentido de conceber tal direito como um

19 "O direito de resistência é um dos temas centrais da denominada Reforma Política. Assim, por exemplo, J. Alsted, colega de Althusius na Universidade de Herborn, defendia: "Gravissima est questio theologico-politica de resistentia tyranni”. Este movimento cultural terá um impacto decisivo no desenvolvimento das instituições político-jurídicas tanto do Estado como da sociedade moderna. Nesta perspectiva o direito de resistência protestante aparece como a base de um dos direitos fundamentais da moderna teoria juspublicista, tal como será posteriormente codificado a partir da Declaração de 1789 e em algumas constituições modernas" (CARVAJAL, 1992. p. 20).

20 Sendo o sistema jurídico uma ordem normativa que reivindica autoridade e que, consequentemente, postula a existência de um dever de obediência, como ensina Raz, coloca-se o problema tanto de demonstrar a existência de tal dever (obrigação política) quanto seus limites, ponto exato em que se aborda o direito de resistência na Teoria e na Filosofia do Direito, ao lado de figuras similares, tais como a revolução e a guerra civil. Sobre o tema, confira-se, entre outros, (RAZ, 1985). Tal autor demonstra também a proximidade do tema em exame com outros, como o da objeção de consciência e da desobediência civil. Rememore-se, por ser oportuno, que DWORKIN considera parte necessariamente integrante de uma Teoria do Direito, a formulação de uma Teoria da Obediência (DWORKIN,2002). $\mathrm{O}$ autor aborda a temática da desobediência civil no Capítulo 8 da mesma obra. Observe-se, adicionalmente, que a temática ora tratada encontra íntima conexão com o problema de injustiça legal tolerável e intolerável e as teorias sobre seus efeitos na validade e eficácia das normas jurídicas, enfrentado inclusive pelo Tribunal Constitucional Federal alemão em importantes precedentes (BVerfGE 23, 98, de 1968, e BVerfGE 34, 269 de 1973) e tratada por Alexy em obra especificamente dedicada a uma visão pós-positivista do Direito.Consulte-se (ALEXY, 2009).

21 É vasta a literatura medieval sobre o tema, e para quem considera a existência de um constitucionalismo medieval, traduzido, no ocidente, especialmente nas tradições britânica, ibérica e francesa, o controle direto de constitucionalidade, traduzido no direito de resistência, era uma das características principais de tal período.

22 É o caso da Constituição Argentina que, por força de uma reforma constitucional no ano de 1994, positivou direitos políticos anteriormente considerados implícitos, passou a incorporar diversos direitos políticos novos, inclusive uma versão do direito de resistência. Como ensina Horácio D’Angelo (1996) trata-se do direito de resistência à interrupção da ordem constitucional, previsto no art. 36 daquela constituição. Dispositivo relativamente semelhante encontra-se na Lei Fundamental alemã de 1949, art. 20 (4).Observa Roberto Gargarella que muitas constituições contemplam dispositivos que preveem direito de resistência contra golpes de Estado.A ideia de um direito de resistência aos atentados à ordem constitucional e democrática podem ser encontrados já no pensamento de LOCKE. (GARGARELLA, 2005).

23 Ressalte-se desde logo tratar-se de variação do direito de resistência no sentido da defesa da ordem constitucional contra atentados a ela perpetrados, prevista no art. 20 (4) da Lei de Bonn.Outras constituições contemplam o direito de resistência, tais como a Constituição de Cabo Verde de 1991, art. 19; a Constituição de Moçambique de 1990, art. 80; a de Portugal de 1976, art. 21 e a Constituição de Timor-Leste de 2002, art. 28. (MOUR ÂO; PORTO; MANTOVANI, 2007). 
instrumento contra o que o autor denomina de alienação legal, que consistiria em um fenômeno pelo qual o direito passaria a servir a finalidades diversas daquelas que originalmente justificariam sua existência. ${ }^{24}$

A conceitualização do direito de resistência é tormentosa, tendo a expressão conhecido os mais variados significados, desde instituto de direito natural até teoria política. Em sentido amplo e baseado em um núcleo de significação que parece informar o conceito seria possível defini-lo com Juan Ignacio Ugartemendia Eceizabarrena como

o direito do particular, ou de grupos organizados, ou de órgãos do Estado, ou de todo o povo, de opor-se, valendo-se de qualquer recurso, inclusive com a força, a um poder ilegítimo ou ao exercício arbitrário e violento, desconforme ao direito, do poder estatal (ECEIZABARRENA, 1999,p. 214)25

Um primeiro aspecto importante a se observar é que uma vez assim definido odireito de resistência resta excluído outros fenômenos de desobediência ${ }^{26}$ ao direito, como a comportamentos criminosos ou a pura e simples desobediência à ordem jurídica sem justificação plausível.Recorda Eicezabarrena $^{27}$ (1999) que a noção de direito de resistência desenvolve-se no pensamento grego antigo, como já mencionado,juntamente com a noção de justiça e com a noção de tirania, que vai adquirindo a conotação de ausência de legitimidade do poder ou de seu exercício, chegando ao tiranicídio.Passando pelo pensamento dos estoicos, o conceito de direito de resistência conhecerá contornos novos sob o cristianismo:

Efetivamente, apesar da doutrina cristã determinar a obediência à autoridade civil, estabelece também que se deve dar a César o que é de César e a Deus o que é de Deus; e se aquele, imiscuindo-se na esfera de Deus, contradiz o que este manda ou proíbe, o cristão tem a obrigação de resistir em obedecer a autoridade civil (obrigação mas não direito a resistir, pois a resistência é concebida neste momento em sua forma passiva (EICEZABARRENA, 1999, 219).

Durante a Idade Média desenvolvem-se as ideias referentes à denominada "resistência eclesiástica", baseada na noção de supremacia da autoridade espiritual sobre a autoridade temporal,

24 Essa ocorrência assumiria diversas formulações, como, por exemplo, a de que o direito de resistência seria legítimo quando o soberano traísse seu país, cometesse abusos de autoridade, se tornasse um opressor de seu próprio povo ou, ainda, atuasse no interesse pessoal (GARGARELLA, 2005).

25 Como ensina Horácio D’Angelo, “esse direito de reação contra o despotismo e a perda de liberdade constitui uma legítima defesa dos direitos humanos. Não se vincula necessariamente com um governo usurpador. Seu exercício se justificaria também em face de um governo legitimamente estabelecido, de acordo com a tradição e a lei. Assim fora concebido em sua origem" (D’ANGELO, 1996, p. 65). Sobre a distinção (ALTHUSIUS, 1995, p. 195-196).

26 Tais como a desobediência civil. Hugo Bedau ensina que um ato de desobediência civil consiste apenas e tão somente na prática de uma ação ilegal de maneira pública e não violenta, com a intenção consciente de frustrar leis, políticas ou decisões do governo. Na mesma esteira do pensamento deste autor, outros, como John Rawls e Ronald Dworkin consideram que a desobediência civil não compreende uma refutação de toda a ordem jurídica, mas de normas específicas integrantes desta(GARGARELLA, 2010,p. 15-16, especialmente a nota de rodapé n. 14.

27 Evidenciam-se desde logo as modalidades de direito de resistência absque titulo e de direito de resistência $a b$ exercitio (ECEIZABARRENA, 1999p. 215).Observa este autor que o ius resistendi da Constituição Estamental, consagrado na Magna Carta de 1215 e em outros documentos históricos, desenvolver-se-á e formalizar-se-á em procedimentos jurídicos concretos para a tutela de direitos e desdobrar-se-á, posteriormente, em procedimento judicial formal contra o rei. Consulte-se a seção n. 61 da Magna Carta de 1215 (ECEIZABARRENA, 1999). 
assim como o direito de resistência germânico da Alta Idade Média, consistente na ruptura do liame de vassalagem entre vassalo e senhor por quebra dos deveres deste.De acordo com o autor,

Esta agregação do direito de resistência germânico e feudal, que se baseia no conceito da fidelidade recíproca, se formalizará na medida em que passam a se objetivar as relações feudais e vão surgindo as corporações estamentais, terminando por institucionalizar-se como direito básico do regnum face ao rex"(EICEZABARRENA, 1999, 219).

Historicamente o direito de resistência prende-se tanto a uma noção contratualista do poder monárquico quanto à noção, em gestação desde a Idade Média, de soberania popular, assentandose especialmente na recusa à concepção do poder do monarca como decorrente de uma cessão irretratável e plena (translatio imperii), em favor em concepções que sustentam uma cessão limitada e condicional (concessio imperii).Nesse contexto, o dever limitado de obediência ao soberano e ao seu direito tem seu correspondente exatamente na noção de direito de resistência. ${ }^{28}$ Observa Eceizabarrena (1999) que a formulação moderna do conceito de direito de resistência surge no contexto das guerras de religião do período da Reforma, sob a influência dos monarcomacos, adversários do absolutismo e da tirania e defensores dos direitos do poder em face do poder real (segunda metade do século XVI).

Apesar do desaparecimento do dualismo que o embasava sob o absolutismo do século XVII, o direito de resistência continua a ser afirmado na Modernidade com bases metapositivas jusnaturalistas (ECEIZABARRENA, 1999). Assim, uma breve análise do pensamento de alguns dos autores clássicos que defenderam o direito de resistência nos séculos XVII e XVIII, a saber, Johannes Althusius e John Locke, será valiosa para a compreensão das questões ora investigadas. ${ }^{29}$

Contrapondo-se à teoria dos jura majestatis inspirada na doutrina da Soberania de Jean Bodin e justificadora do absolutismo, Althusius desenvolve o conceito de jura republicae, considerada por Patricio Carvajal como a fonte da moderna teoria dos direitos fundamentais.Em sua obra principal, "Politica Methodice Digesta atque Exemplis Sacris et Profana Illustrata"30, Althusius propõe diversas razões para o exercício do direito de resistência, algumas de cunho religioso, outras de cunho laico (CARVAJAL, 1992).

Sem a intenção de reproduzir todas as teses de Althusius no particular, exploraremos aqui alguns argumentos seus, focando especialmente nos argumentos de caráter laico, a partir do

28 Tais concepções são anteriores à consolidação das doutrinas do direito divino absoluto, que propugnam a inviolabilidade do monarca e dão embasamento ideológico ao advento das monarquias absolutistas. Note-se ser bastante plausível a influência de concepções medievais com a da distinção entre rex e regnum e das doutrinas contrapostas da translatio e da concessio imperii sobre o ideário liberal moderno e o contratualismo de autores como Hobbes e Locke (ECEIZABARRENA, 1999).A mais sofisticada expressão de tal concepção encontrar-se-á no pensamento de Althusius (CARVAJAL, 1992).

29 Patrício Carvajal evidencia que, as relevantes reflexões de Johannes Althusius sobre o direito de resistência remonta à polêmica mantida entre este autor e Henning Arnisaeus, reputando-a como a mais profunda e decisiva discussão havida no seio do protestantismo alemão do período, que estaria, segundo o autor, na origem do constitucionalismo alemão moderno. Alguns aspectos do pensamento de Althusius influenciaram inclusive as teorizações de Locke sobre o direito de resistência (CARVAJAL, 1992).

30 Alguns aspectos do pensamento de Althusius influenciaram inclusive as teorizações de Locke sobre o direito de resistência (CARVAJAL, 1992). 
Capítulo XXXVIII de sua obra, intitulado "Tirania e seus remédios".

Entre as reflexões althusianas sobre o tema cabe destacar preliminarmente a noção basilar de mutua obligatio, ou obrigação recíproca, de acordo com a qual o contrato entre magistrados e cidadania reclama dos primeiros uma atuação nos termos do referido contrato ou acordo, sob pena de revogação do mandato pela última.A noção de mutua obligatio implica ainda a existência de limites às obrigações dos governados em face dos governantes, concebendo-se inclusive que certas obrigações legais poderiam ser superadas por outras obrigações naturais ${ }^{31}$ (CARVAJAL, 1992).

Althusius sustenta também existirem limites à atuação dos magistrados (i.e., oficiais públicos), como, por exemplo, aqueles impostos pelas leis fundamentais do reino, cuja violação seria apta a justificar a desobediência do povo.Também o conflito da lei positiva com a lei divina ou lei natural faria com que a primeira, carecendo de conteúdo justo, não merecesse observância por seus destinatários.Johannes Althusius afirmava ainda que a tirania seria contrária ao contrato social, razão pela qual o governante tirano perderia sua condição peculiar, convertendo-se em simples particular, ao qual os demais poderiam opor resistência, uma vez que não mais lhe deveriam obediência. ${ }^{32}$ (ALTHUSIUS, 1995).

Deve-se observar, contudo, que o pensamento do autor alemão admite o direito de resistênciaapenas como ultima ratio, exigindo o esgotamento das demais alternativas eficazes, afirmando o mesmo que

(...) outros remédios que não a deposição para dobrar e controlar a tirania devem ser experimentados primeiramente, repetidamente, até que reste demonstrado serem ineficazes, de modo que o remédio não se torne mais perigoso do que a própria doença (ALTHUSIUS, 1995, § 59, p. 27).

Por outro lado, de acordo com o pensamento do monarcomaco, a resistência estaria tanto mais justificada quanto mais irreparável fosse a injúria: "quando houver risco na demora, quando o mal cresce e ganha força, deve-se resistir imediatamente e confrontar o tirano corajosamente desde logo, e não após certo tempo.’(ALTHUSIUS,1995, p. 195, § 60).

Althusius sustenta que embora possa ser exercido por palavras e ações, o direito de resistência deveria ser manejado defensiva, e não ofensivamente.Além disso, o autor afirma que "deve haver resistência enquanto perdurar a tirania, e enquanto ela assaltar ou atuar contra o pactuado", de modo que "a tirania deve ser objeto de resistência até que a comunidade seja restaurada a seu estado original." (ALTHUSIUS, 1995, p. 196, § 63)Além disso, o mesmo sustentava que na ausência de um juiz ou em caso de omissão deste, por prevaricação, omissão ou outra razão, o povo converterse-ia em juiz, podendo chegar às raias da resistência armada ${ }^{33}$ (ALTHUSIUS, 1995).

31 Vislumbra-se aqui, em fase embrionária, a discussão acerca da obrigação política e do dever de obediência ao direito (CARVAJAL, 1992).

32 Novamente é enorme a semelhança entre De Politica Methodice Digesta e o Segundo Tratado Sobre o Governo Civil (CARVAJAL, 1992).

33 Sustenta Althusius que para restaurar a condição original da comunidade, "os nobres podem remover tal pessoa de suas funções, privando-a da administração que lhe foi confiada, e, se forem incapazes de defender-se por quaisquer outros meios contra a força, podem até mesmo matá-lo e colocar outrem em seu lugar" (ALTHUSIUS, 1995,p. 196, $\S 63)$. Embora na teoria do autor alemão o direito de resistência e o correlato dever de proteção da comunidade 
Um último e relevante aspecto a se ressaltar sobre as teses de Althusius acerca do direito de resistência é o argumento sobre sua necessidade ou imprescindibilidade. Carvajal sustenta que, na época do autor calvinista, o direito de resistência operaria como uma espécie de controle constitucional dos atos dos governantes, na ausência de instituições próprias, pelo que, na visão de Althusius, caso fosse suprimido o direito de resistência, consagrar-se-ia a liberdade plena para os tiranos $^{34}$ (CARVAJAL, 1992).

Obviamente não se poderia deixar, aqui, de visitar, ainda que brevemente, também o pensamento de John Locke sobre a temática, que é explorada no Capítulo XIX do Segundo Tratado Sobre o Governo, intitulado "dissolução do governo". Distinguindo, como é sabido, as hipóteses de dissolução da sociedade e de dissolução do governo, Locke afirma:

Se um homem ou grupo arrogarem para si a elaboração de leis sem que o povo os tenha eleito para tanto, serão leis sem autoridade, a que o povo, em consequência, não está obrigado a obedecer. Em tais condições, o povo estará novamente desvinculado de sujeição, podendo constituir novo legislativo do modo que julgar melhor, tendo inclusive toda liberdade de resistir à força aos que, sem autoridade, quiserem impor-lhe seja lá o que for (LOCKE, 2002, p. 137)

Entre as várias hipóteses de dissolução do governo examinadas por Locke encontram-se, exemplificativamente, as modificações do legislativo levadas a cabo por meio do exercício de competências legisferantes pelo príncipe de maneira arbitrária; pelo impedimento da reunião do legislativo pelo príncipe, ou, ainda, por alterações dos procedimentos eleitorais em prejuízo ao eleitorado.Também nos casos de abandono do Poder Executivo e de recusa à administração da justiça na ótica lockeana o povo ficaria livre para instituir novo governo, em virtude do direito natural de autopreservação que lhe caberia (LOCKE, 2002).

Locke aduz que "um governo, portanto, pode ser dissolvido ainda de outro modo, que é o agir do legislativo ou do executivo contrariamente à intenção que lhe outorgou o poder" (LOCKE, 2002, p. 140).Especialmente os atentados contra a propriedade, a vida ou a liberdade dos súditos

coubesse exclusivamente aos nobres (que atuariam como "éforos" ou controladores do governante supremo, com inspiração na magistratura espartana), Althusius admitia excepcionalmente o exercício da resistência violenta para os plebeus, desde que isso fosse indispensável para a defesa de suas vidas (ALTHUSIUS, 1995). Consigne-se que parece haver uma vinculação importante entre o direito de resistência e figuras jurídicas como a legítima defesa e o estado de necessidade. Por outro lado, também se encontra presente a noção de proporcionalidade no pensamento do autor alemão, pois como ensina Carvajal, "em qualquer caso antes de chegar à resistência armada, Althusius indica vários procedimentos, que vão desde a admoestação verbal até o comparecimento da autoridade perante os éforos. Somente como ultima ratio está contemplada a resistência" (CARVAJAL, 1992, p. 28). Além disso, o monarcomaco insiste que não seria qualquer falha do governante que o tornaria um tirano e que, portanto, justificaria a resistência, mas apenas e tão somente aquelas de maior gravidade. (ALTHUSIUS, 1995).

34 Aqui o direito de resistência é concebido evidentemente como uma garantia. Também Locke faz ponderações semelhantes, ao afirmar que "os homens nunca estarão seguros contra a tirania se não houver algum meio de evitá-la antes que estejam a ela submetidos; portanto esta é a razão porque têm não apenas o direito de livrar-se dela, mas também o de impedir que se instale" (LOCKE, 2002,p. 140). Interessante observar que o direito de resistência como concebido por Althusius conecta-se inclusive com um possível direito de secessão: "Um dos Estados, ou uma parte do reino, pode abandonar o restante do corpo ao qual pertencia e escolher para si mesma outro governante ou uma nova forma de comunidade quando o exigir pública e manifestamente o bem-estar de sua totalidade, ou quando leis fundamentais do país forem descumpridas pelo magistrado, sendo obstinadamente e de maneira ultrajante violadas, ou quando o verdadeiro respeito e o comando evidente de Deus claramente exigir e requerer que tal seja feito. Em tais circunstâncias esta parte do reino pode defender pela força e pelas armas sua nova forma e status contra as demais partes do reino da qual se desligou" (ALTHUSIUS, 1995p. 197 § 76). 
ensejariam a dissolução do governo, com a consequente cessação do dever de obediência e emergência de um contexto de exercício legítimo do direito de resistência, no pensamento do jusfilósofo inglês:

A razão básica que leva os homens a se juntarem em sociedade é a preservação da propriedade; e a finalidade para a qual elegem e dão autoridade a um poder legislativo é possibilitar a existência de leis e regras definidas que sejam guardiãs e protetoras da propriedade dos membros da sociedade, limitando assim o poder e controlando o domínio de cada parte e de cada membro; pois é inimaginável supor como vontade da sociedade que o legislativo tenha a possibilidade de destruir justamente aquilo que todos querem garantir entrando em sociedade, $\mathrm{e}$ para o que o povo aceita obedecer a legisladores que ele mesmo escolhe. Sempre que o legislativo tentar tomar ou destruir a propriedade do cidadão, ou subjugá-lo ao seu poder arbitrário, entra em estado de guerra com ele, isentando-o de ulterior obediência, deixando-o à mercê de Deus, que provê para todos os homens contra a força e a violência (LOCKE, 2002, p. 140-141).

Trata-se da ruptura do pactum subjectionis por infidelidade dos representantes, que caracteriza a teoria contratualista lockeana e que se aproxima das noções anteriores de mutua obligatio, distinguindo-se de orientações como as de Thomas Hobbes, Sir Robert Filmer e Henning Arnisaeus. O raciocínio de Locke aplica-se tanto ao Poder Legislativo quanto ao Poder Executivo, quando qualquer deles atentar contra a vida, a propriedade e os bens dos membros da sociedade política. $^{35}$

Na visão de Locke, a legitimação do direito de resistência encontraria seu fundamento na traição da vontade popular, nos abusos vinculados ao exercício tirânico do poder e aos caprichos do governante, pelo abandono da razão e da legalidade e sua substituição pela violência. Segundo essa corrente de pensamento, o uso da violência pelo governante o reduziria à condição das demais feras e consequentemente teria o condão de restaurar o direito dos governados de tratá-lo da mesma maneira que fariam com aquelas. Além disso, causaria um retorno ao estado de guerra, legitimando, assim, o direito de resistência por parte dos governados (GARGARELLA, 2007).

Uma vez feito este breve resgate de alguns importantes precedentes históricos e teóricos referentes ao direito de resistência, cabe indagar se na contemporaneidade ainda haveria possibilidade de sustentar a existência do referido direito para compreender fenômenos como as manifestações violentas.

\section{DIREITO DE RESISTÊNCIA, O “DIREITO PERDIDO”.}

A despeito da importância da ideia de direito de resistência no pensamento político e jurídico medieval e moderno, percebe-se uma impressionante ausência de estudos do direito de resistência no Direito Constitucional contemporâneo, como observa Roberto Gargarella (2005, p.

35Vários fatos seriam capazes a ensejar a resistência segundo Locke, como, por exemplo, o confisco da propriedade, o arbítrio, o atentado à vida, à liberdade, a corrupção, o aliciamento de eleitores, as ameaças, entre outras (LOCKE,2002). 
04), que chega a chamá-lo de "direito perdido".

$\mathrm{O}$ autor argentino observa que o direito de resistência foi paulatinamente perdendo a centralidade e desaparecendo nos discursos políticos e jurídicos, e aponta algumas possíveis causas do fenômeno, tais como a dispersão dos centros de poder na atualidade, entre outras, inclusive possivelmente por força de seus próprios êxitos (GARGARELLA, 2005).

Como ensina Rawls, uma diferença entre o constitucionalismo medieval e o moderno está no fato de que, no primeiro, a supremacia da lei [in recto: do direito] não era garantida por controles institucionais estabelecidos. "O controle sobre o governante que em suas sentenças e leis contrariava o senso de justiça da comunidade restringia-se, em sua essência, ao direito de resistência da sociedade em seu todo ou em parte" (RAWLS, 2000, p. 427).

Interessante observar que a própria nova configuração das instituições democráticas e constitucionais, que hauriram boa parte de sua força exatamente na ideia de resistência à injustiça ou ao arbítrio,poderia ser uma das razões capazes de explicar o paulatino desaparecimento da ideia da possibilidade de resistência à autoridade do imaginário político e jurídico. Anova organização institucional do Estado,informada pela separação dos poderes, juntamente com o sistema de checks and balances, teria reduzido o risco de uma transformação do direito em um instrumento de opressão:

De modo igualmente significativo, este sistema inclui numerosas ferramentas destinadas a facilitar ou promover, de modo pacífico e ordenado, mudanças políticas - e mesmo mudanças de matizes radicais. As eleições periódicas, em particular, revelam-se decisivas nesta discussão, ao marcar uma diferença crucial entre o nosso tempo e o passado (GARGARELLA, 2005, p. 14).

Nessa linha de pensamento, sob o novo panorama democrático e institucional, teria ocorrido uma modificação das condições políticas que explicaria o desaparecimento da anterior ênfase no direito de resistência, tendo este deixado de ser concebido como único mecanismo apto a garantir a responsabilidade dos governantes. $\mathrm{O}$ mesmo se aplicaria às possibilidades de modificação de elementos como o sistema ou a forma de governo, através de reformas constitucionais, sem necessidade de recurso à força. Tais mudanças explicariam não apenas o paulatino desaparecimento da noção do direito de resistência do pensamento político e jurídico contemporâneo, mas também sua substituição pelos conceitos de objeção de consciência e de desobediência civil, que passam a ser concebidoscomo os atos mais extremos aceitáveis na nova ambiência institucional democrática (GARGARELLA, 2005).

Apesar disso, Gargarella (2007)observa que a privação de parte da população quanto à satisfação de necessidades básicas, em virtude da pobreza, consistiria violação de direitos humanos, o que poderia gerar um questionamento acerca da manutenção do dever de obediência ao direito por parte de populações em situação de carência extrema e a cogitar sobre a possibilidade de exercício legítimo de direito de resistência em tais circunstâncias. ${ }^{36}$

36 Interessante transcrever um trecho do Segundo Tratado sobre o Governo de Locke, bastante pertinente: “Quando o povo está na miséria, exposto aos desmandos do poder arbitrário, podem chamar os governantes de filhos de Júpiter, 
Segundo tal linha de pensamento, seria possível reconhecer que situações de carência extrema, pela não-satisfação de necessidades básicas e irrealização de direitos fundamentais sociais e econômicos, poderiam indicar situações de alienação legal, no sentido referido acima ${ }^{37}$, ressaltando-se que esta é uma hipótese interessante formulada pelo autor latino-americano que não exclui outras situações extremas em que o exercício de tal direito igualmente poderia se legitimar.

Mario Meneghiniobserva existirem diversos tipos de resistência, para aqueles que reconhecem o controvertido direito, tais como a resistência passiva, a resistência ativa - jurídica ou de fato - e, ainda, a rebelião (MENEGHINI, 2011).

$\mathrm{Na}$ mesma esteira, Gargarella (2005)distingue o direito de resistência concebido de forma negativa - como não-cooperação - do direito de resistência concebido de forma ativa como confrontação, denominando-os respectivamente de resistência passiva e resistência ativa, considerando que ambas as formas de resistência seriam, em princípio, admissíveis, sob algumas condições (substanciais e procedimentais) e dentro de alguns limites.

Para Meneghini (2011), considerar-se-ia legítima a resistência de fato ou a rebelião, inclusive com recurso ao uso de armas, em caso de opressão pelos governantes que reúna alguns requisitos, notadamente: violações certas, graves e prolongadas dos direitos fundamentais; esgotamento dos demais recursos; que não provoque desordens ainda piores; que tenha fundada expectativa de êxito e, ainda, na impossibilidade de encontrar soluções melhores a partir da razoabilidade ${ }^{38}$. Como se vê, a literatura tem procurado estabelecer critérios e limites para que se possa reconhecer excepcionalmente o exercício legítimo do direito em comento.

Abordando tais requisitos, Gargarella (2005, p. 20-21) defende a necessidade de encontrarse aberta a revisão a questão de causalidade, pois observa o mesmo que "em muitas ocasiões, com efeito, seria irrazoável acusar o Estado pela miséria dos mais desfavorecidos”, observando, antes de tudo, que a possibilidade de que "o Estado não conte com melhores alternativas à sua disposição, para assegurar que não haja grupos sistematicamente privados de certos bens básicos."

Além disso, o direito de resistência estaria condicionado a uma exigência de mútuo respeito, não podendo ser interpretado como uma carta branca para que alguém, a pretexto de exercê-lo, arrogue-se no direito de agir como bem entender contra autoridades e contra os demais particulares. ${ }^{39} \mathrm{Nesse}$ sentido, ao tratar do problema da desobediência civil, afirma Dworkin que

quer sejam eles sagrados ou divinos, descendentes do céu ou portadores de sua autorização, conclamem quem ou o que quiser -, a rebelião acontecerá. O povo maltratado e injustiçado estará sempre disposto a livrar-se do peso que o oprime" (LOCKE, 2002,p. 142).

37 Gargarella interpreta a privação na satisfação de necessidades fundamentais, como alimentação e moradia, como a condição substantiva, e seu caráter sistemático, como a condição procedimental do direito de resistência: "Obviamente, aqueles que se veem sistematicamente privados de abrigo ou moradia; aqueles que sofrem diariamente com a fome; aqueles que são vítimas sistemáticas da violência, etc., enfrentam alguns dos piores prejuízos que uma pessoa pode enfrentar (condição substantiva). Ao mesmo tempo, tais ofensas, e particularmente seu caráter sistemático, indicam a existência de graves deficiências procedimentais - deficiências que se vinculam com o sistema institucional, e que mostram que o mesmo é incapaz de reparar os males existentes. Em tais situações, revela-se muito difícil não culpar o sistema institucional pelos males de que padecem os membros destes grupos marginalizados."(GARGARELLA, 2005, p. 18).

38 Observa o autor que tais exigências buscam evitar insurreições ou guerras civis nas ocasiões em que não estejam presentes as condições mínimas necessárias à garantia do bem comum, para não se combater um mal com um mal ainda maior (MENEGHINI, 2011).

39 Aqui o autor evoca o pensamento de Rawls e noções como a de deveres morais básicos, chamados deveres naturais por aquele, ligados às noções de respeito e de reciprocidade (GARGARELLA, 2005). 
(...) se uma regra jurídica específica representa uma decisão oficial que estabelece que os indivíduos têm o direito moral de não sofrerem uma determinada lesão, estamos diante de um poderoso argumento contra a tolerância às violações que infligem esses danos. Por exemplo, as leis que protegem os indivíduos contra danos pessoais ou contra a destruição de suas propriedades representam tal tipo de decisão, e este é um argumento muito forte contra a tolerância da desobediência civil que envolve a prática da violência (DWORKIN, 2002, p. 333).

Enfrentando o tema da desobediência civil, que embora não se confunda com o do direito de resistência, do ponto de vista aqui adotado, possui fortes conexões com este, Rawls postula a existência de um dever de obediência ao direitoprima facie, embora isso somente seja válido sob determinadas condições indicadas pelo autor, notadamente a caracterização de um estado de quasejustiça e a presença de uma constituição justa, no sentido que o autor atribui a estas expressões (RAWLS, 2000).

Ou seja, ausentes tais pressupostos, de acordo com a influente Teoria da Justiça formulada pelo autor, torna-se problemática a afirmação de tal dever de obediência ${ }^{40}$ e reforça as teses que afirmam o um direito de resistência, ainda que excepcional. Observe-se que ainda nestes sistemas políticos quase-justos, no qual mesmo normas injustas devem em princípio ser obedecidas, pelos fundamentos expostos por RAWLS (2000, p. 401)existiriam limites para o dever de obediência,"contudo, nosso dever natural de apoiar instituições justas nos obriga a acatar leis e políticas injustas, ou pelo menos a não fazer-lhes oposição usando meios ilegais, desde que elas não ultrapassem certos limites de injustiça."

Voltando ao pensamento de Gargarella (2005), o exercício do direito de resistência estaria vinculado, ainda, a uma condição denominada questão de vínculo ou nexo, que se traduziria na ponderação de que a resistência legítima tende a verificar-se nas áreas nas quais os seus exercentes encontram-se prejudicados.

Por fim, mas não de menor importância, verifica-se um importante limite consistente na proporcionalidade, imperativo de acordo com o qual não poderiam os excluídos, ao exercer o direito de resistência, impor sacrifícios desnecessários ao restante da comunidade, exorbitando em seu exercício.No mesmo sentido é o magistério de Marta Salazar Sánchez, que observa que

o exercício do direito [de resistência] conhece certas restrições ou parâmetros de ação formulados pela doutrina para evitar-se cair em arbitrariedades. Apenas na hipótese de se respeitarem certas normas de conduta a ação é considerada jurídica e protegida pelo direito: os meios empregados devem ser apropriados, necessários e guardar relação com as circunstâncias. A doutrina indica que devem ser utilizados os meios mais suaves (milder), desde que sejam efetivos (SÁNCHEZ, 1993, p. 230)

40 Nas palavras do autor, a teoria por ele formulada (quanto ao dever de obediência ao direito e a possibilidade de desobediência), pressupondo um regime democrático, "não se aplica a outras formas de governo nem, exceto incidentalmente, a outras formas de dissensão ou resistência. Não discutirei essa modalidade de protesto associando-a à ação armada e à resistência, como uma tática para transformar ou mesmo derrubar um sistema corrupto e injusto. Não há nesse caso dificuldade a respeito da desobediência civil’(RAWLS, 2000, p. 402) 
Com efeito, mesmo que seja reconhecido, o direito de resistência consistiria em um direito excepcional cujo exercício se revelaria possível apenas e tão-somente em situações absolutamente anômalas, de forma análoga a outras figuras já consagradas juridicamente, como a legítima defesa e o estado de necessidade. Em decorrência disso, o direito de resistência ostentaria caráter subsidiário, que se traduz na exigência de que se tenham esgotado todos os demais recursos disponíveis para a defesa dos interesses cuja violação se pretende evitar ou repelir, em virtude de que o referido direito deve ser concebido como ultima ratio (SÁNCHEZ, 1993).

De se observar ainda que o direito de resistência, em sua formulação clássica, somente poderia ser exercido legitimamente contra órgãos estatais e jamais contra particulares, de modo que, ao se analisar a legitimidade do exercício do direito de resistência, seria necessário distinguir as ações contra os responsáveis por atos arbitrários ou ilegítimos e as ações contra terceiros (SÁNCHEZ, 1993).

Embora seja extremamente complexa a questão da existência e dos limites do direito de resistência, parece que as ponderações feitas pela doutrina acerca do mesmo podem auxiliar na aproximação de algumas respostas sobre uma possível relação entre atos de violência no âmbito de manifestações e aquele direito.

\section{CONCLUSÃO}

Embora o presente artigo não tenha a pretensão de oferecer respostas conclusivas ao complexo problema examinado, algumas conclusões provisórias parecem ser possíveis. Primeiramente parece possível sustentar ser pouco plausível entender que atos de violência encontrem amparo no direito ao protesto em um regime democrático, uma vez que parece existir, no próprio cerne da noção de democracia, uma renúncia ao recurso aos meios violentos (o que se manifesta, inclusive, em proibições constitucionais recorrentes a partidos e organizações de caráter paramilitar, entre outras coisas).

Não obstante impõe-se reconhecer a legitimidade das manifestações populares, apesar de eventuais excessos, e compreender o fenômeno no atual contexto de certo esbatimento da democracia representativa, quetem se revelado incapaz de dar vazão, pelos meios institucionais próprios,a diversos anseios da população que parecem bastante legítimos, se não caracterizando pelo menos se aproximando bastante de uma situação de alienação legal para vários segmentos da população, especialmente em casos como o brasileiro.

O que seria possível questionar é se a situação de alienação legal referida, cuja existência parece plausível admitir, seria grave o suficiente para justificar o recurso ao emprego de violência e aos atos de depredação de patrimônio público e privado que se verificaram no país notadamente no ano de 2013. Como visto da breve incursão feita na doutrina política e jurídica, o direito de resistência configura a ultima ratio para os casos de alienação legal, exigindo a doutrina que a ele se dedicou a presença de uma série de requisitos substanciais e procedimentais para reconhecer 
seu exercício legítimo.

Assim, caberia indagar se a situação do país seria de tal gravidade a ponto de configurar-se a situação de alienação legal para a qual Gargarella (2007) hipoteticamente admitiria o exercício do direito de resistência, como visto.Obviamente pode haver discordância sobre a caracterização ou descaracterização desta situação, a depender dos pontos de vista adotados.

Por outro lado, mesmo que se passe ao largo de tal indagação preliminar, admitindo-se por hipótese a possibilidade de vislumbrar-se o uso da violência como amparado pelo direito de resistência em virtude da configuração de uma situação de alienação legal,com a consequente cessação do dever de obediência ao direito pela população, caberia refletir sobre outros aspectos levantados pela literatura que se dedicou à temática.

Em primeiro lugar, considerando-se o caráter residual do direito de resistência, haveria que se questionar se todos os demais recursos potencialmente efetivos teriam sido tentados antes de se buscar amparo na resistência pela força. Assim, seria cabível questionar se haveriam outros meios de manifestação do descontentamento com as instituições político-representativas e com os resultados concretos de sua operação que não implicassem o recurso à violência.

Nesse contexto, convém recordar, na esteira dos ensinamentos teórico-práticos de importantes pensadores e líderes políticos da história mundial, existem inúmeras formas de intervenção política que dispensam o recurso à mínima violência.Atos de desobediência civil passiva e pacífica, ou o recurso a boicotes, além das próprias manifestações pacíficas, seriam exemplos. Hipoteticamente, uma advertência muito clara aos governantes poderia concretizar-se por uma ausência massiva às urnas, ou por um volume massivo de votos nulos nas eleições.Com recurso às modernas tecnologias de informação e comunicação, seria possível pensar ainda em outros atos de enorme impacto, como o boicote a determinados produtos ou serviços, ou a frustração de determinados objetivos governamentais pela ação coordenada da cidadania(SARDINA-PÁRAMO, 1976).

Enfim, é possível, ao menos teoricamente, cogitar diversos atos concretos que, ao lado de manifestações pacíficas, poderiam traduzir-se em recursos potencialmente eficazes para provocar uma reação das autoridades eleitas e, eventualmente, superar pelo menos alguns aspectos da alienação legal - em tese, frise-se.

Seria necessário evidenciar que tais recursos tivessem sido tentados e tivessem se revelado sistematicamente ineficazes, para ser possível reconhecer estarem os atos de violência praticados por ocasião das manifestações amparados pelo direito de resistência.

Além disso, convém refletir sobre outros requisitos apontados pela doutrina como condições para o legítimo exercício da resistência. Pode-se questionar, por exemplo, se as exigências naturais do mútuo respeito e da proporcionalidade teriam sido observadas.

Como é sabido, durante os protestos houve atos de depredação de patrimônio público e privado e, no último caso, não apenas contra o patrimônio de instituições financeiras e corporações (consideradas por parcela dos manifestantes como culpadas por diversos dos males contemporâneos), mas também o de particulares que não tinham qualquer culpa pela situação contra a qual se protestava e que tiveram seu patrimônio violado, através de atos de vandalismo 
contra automóveis ou estabelecimentos comerciais, ou ainda de saques aos últimos.

Tal quadro poderia evidentemente ser interpretado como violação à exigência do mútuo respeito e, no último caso, como pura e simples prática de atos criminosos aproveitando-se do pretexto das manifestações.Os atos de vandalismo e depredação, e de violência contra pessoas, dificilmente atenderiam o requisito de proporcionalidade apontado por vários autores.

Desse modo, quanto à indagação no sentido de estar o emprego da violência por ocasião das manifestações populares iniciadas em exame protegido pelo direito de resistência, a resposta inicial parece ser negativa.

Por outro lado, deve-se tentar conservar uma perspectiva ampla e tanto quanto possível imparcial, no sentido de reconhecer, na esteira dos pensamentos de Thomas Jefferson, que embora tais comoções possam representar elevados custos, elas também proporcionam benefícios, especialmente em manter o poder estatal dentro de limites.Consigne-se, portanto, que tais ações, ostentando também um caráter de benefício público, não deveriam ser criminalizadas ou reprimidas exageradamente, pois fazem parte de um elemento crítico inerente e salutar à democracia.Como observa GARGARELLA (2005, p. 26), para Jefferson "deve-se atuar muito cuidadosamente em face de tais fatos, dado que a penalização severa dos mesmos poderia implicar "a supressão da única salvaguarda da liberdade pública”.

Isso não significa, por outro lado, que não devam ser observados critérios e limites, e que manifestantes possuam uma carta branca para violar direitos de terceiros - inclusive outros particulares - e que o Estado possa livremente omitir-se em manter uma situação de mínima normalidade.

Quanto à atuação das forças de segurança pública, no particular, as exigências à estrita observância dos direitos humanos dos manifestantes - mesmo dos manifestantes violentos - é imperativa, e a visão segundo a qual os procedimentos da primeira devem se pautar por diversos critérios de justiça e razoabilidade, examinado acima, igualmente.

Duas considerações conclusivas são cabíveis. Primeiramente deve-se estar atento para não confundir os atos de violência em referência com as próprias manifestações, pois os fenômenos não se confundem e são irredutíveis um ao outro.As manifestações referidas são atos políticos perfeitamente legítimos e terão tal legitimidade tanto mais clara quanto mais pacífico for o seu caráter, correndo o risco de ter a percepção social de sua legitimidade prejudicada pelo fato dos atos de violência e de vandalismo roubarem a cena.

Em segundo lugar, parece possível sustentar que tanto de um ponto de vista ético e jurídico quanto de pontos de vista pragmáticos, estratégicos e táticos, a melhor e mais democrática alternativa parece ser a dos meios pacíficos de resistência, como, além das manifestações pacíficas, a simples desobediência civil, os boicotes e outros atos de não-cooperação passiva.

Diversos fatos históricos corroboram as potencialidades transformadoras de ações coletivas concertadas que sistematicamente renunciem o recurso ao emprego de qualquer tipo de violência. Ao que parece o avanço democrático encontra-se indissociavelmente vinculado à compreensão e assunção de um vínculo constitutivo e genético profundo existente entre democracia e meios 
pacíficos e não violentos de ação política, pelo que parece plausível sustentar que a assunção da democracia implica em uma intrínseca renúncia ao uso da força, ressalvadas situações extremas.

Isso não deve ser interpretado, no entanto, uma recusa pura e simples à possibilidade de cessação da obrigação política, entendida como o dever prima facie de obediência ao direito, e de exercício do direito de resistência, inclusive com recurso à força, se necessário, em situações extremas, notadamente em situações de alienação jurídica.

\section{REFERÊNCIAS}

ALEXY, Robert. Conceito e validade do Direito. Trad. Gercélia B. O. Mendes. São Paulo: Martins Fontes, 2009.

ALTHUSIUS, Johannes. Politica: An Abridged Translation of Politics Methodically Set Forth and Illustrated with Sacred and Profane Examples. Trad. Frederick S. Carney. Indianapolis: Liberty Fund, 1995.

ANISTIA INTERNACIONAL. El derecho a la protesta pacifica.Amnistía Internacional Revista sobre Derechos Humanos, Madrid, n. 98, p. 3, 2009.

ARTESE, Matías. Criminalización de la protesta em Argentina: una construcción de lo delitivo más allá de la esfera jurídica.América Latina Hoy,Salamanca, n. 52, pp. 149-169, 2009.

BRASIL. Constituição da República Federativa do Brasil de 1988. Brasília, DF: Presidência da República, 2019. Disponível em: http://www.planalto.gov.br/ccivil_03/Constituicao/ Constituiçao.htm. Acesso em: 4 dez. 2019.

CARVAJAl A., Patricio. Derecho de resistencia, derecho a la revolución, desobediência civil. Revista de Estudios Políticos (Nueva Época),Madrid, n. 76, p. 63-101, 1992.

D'ANGELO, Horacio. Derechos politicos en la constitucion.FACES: Revista de la Facultad de Ciencias Económicas y Sociales, Mar del Plata, n. 2, p. 63-74, 1996.

DAHL, Robert. Poliarquia: participação e oposição. Trad. Celso M. Paciornick. São Paulo: Edusp, 2012.

DUPUIS-DERI, Francis. Penser l'action directe des Black Blocs.Politix: Revue des Sciences Sociales du Politique, Paris, n. 68, p. 79-109, 2004.

DWORKIN, Ronald.Levando os direitos a sério.Trad. Nelson Boeira. São Paulo: Martins Fontes, 2002.

ECEIZABARRENA, Juan Ignacio Ugartemendia. El Derecho de resistência y su constitucionalización.Revista de Estudios Políticos (Nueva Época),Madrid, n. 103, p. 213-245, 1999.

GARGARELLA, Roberto. El derecho de resistencia en situaciones de carência extrema. Astrolabio Revista Internacional de Filosofía, Barcelona, n. 4, pp. 01-29, 2007.

GARGARELLA, Roberto (org.).El derecho a resistir el derecho. Madri: Miño Dávila, 2005. 
LACHAPELLE, Jean; WAY, Lucan; LEVITSKY, Steven. Crisis, Coercion, and Authoritarian Durability: Explaining Diverging Responses to Anti-regime Protest in Egypt and Iran (2012). American Political Science Association Annual Meeting, New Orleans, 31 August 2012.

LOCKE, John.Segundo Tratado sobre o governo. Trad. Alex Marins. São Paulo: Martin Claret, 2002.

MENEGHINI, Mario. Dilema: derecho di resistencia o acción politica.La Razón Histórica:

Revista Hispanoamericana de Historia de las Ideas Politicas y Sociales,Murcia, n. 16, p. 4-9, 2011.

MOURÃO, Fernando Augusto Albuquerque; PORTO, Walter Costa; MANTOVANI, Thelmer Mário. As Constituições dos Países de Língua Portuguesa Comentadas. Brasília: Editora do Senado Federal, 2007.

PERSONERIA DE MEDELLÍN. Protesta social: entre derecho y delicto.Pensamiento Polítiko, Medellín, n. 2, p. 133-144, 2010.

RAWLS, John.Teoria da Justiça, uma. Trad. Almiro Pisetta; Lenita M. R. Esteves. São Paulo: Martins Fontes, 2000.

RAZ, Joseph. Autoridad del Derecho, la: ensayos sobre derecho y moral. Trad. Rolando Tamayo y Salmorán. 2 ed. Cidade do México: Universidade Autônoma do México, 1985.

SÁNCHEZ, Marta Salazar. Positivación del Derecho de Resistencia em el Derecho Constitucional Alemán.Revista Chilena de Derecho, Santiago,v. 20, p. 323-332, 1993.

vSARDINA-PÁRAMO, Juan Antonio. Voto em blanco, abstencionismo electoral y derecho de resistencia,Persona y Derecho: Revista de Fundamentación de las Instituciones Jurídicas y de Derechos Humanos, Pamplona, n. 3, p. 231-246, 1976.

WALZER, Michael. Obligations: Essays on Disobedience, War and Citizenship. Cambridge: Harvard University Press, 1970.

Recebido em: 23/10/2019.

Aprovado em: 15/10/2019. 